\title{
ARTICLE
}

Translational Therapeutics

\section{Reversal of glucocorticoid resistance in paediatric acute lymphoblastic leukaemia is dependent on restoring BIM expression}

\author{
Cara E. Toscan ${ }^{1}$, Duohui Jing ${ }^{1}$, Chelsea Mayoh ${ }^{1}$ and Richard B. Lock ${ }^{1}$
}

BACKGROUND: Acute lymphoblastic leukaemia (ALL) is the most common paediatric malignancy. Glucocorticoids form a critical component of chemotherapy regimens and resistance to glucocorticoid therapy is predictive of poor outcome. We have previously shown that glucocorticoid resistance is associated with upregulation of the oncogene C-MYC and failure to induce the proapoptotic gene BIM.

METHODS: A high-throughput screening (HTS) campaign was carried out to identify glucocorticoid sensitisers against an ALL xenograft derived from a glucocorticoid-resistant paediatric patient. Gene expression analysis was carried out using Illumina microarrays. Efficacy, messenger RNA and protein analysis were carried out by Resazurin assay, reverse transcription-PCR and immunoblotting, respectively.

RESULTS: A novel glucocorticoid sensitiser, 2-((4,5-dihydro- $1 \mathrm{H}$-imidazol-2-yl)thio)- $N$-isopropyl- $N$-phenylacetamide (GCS-3), was identified from the HTS campaign. The sensitising effect was specific to glucocorticoids and synergy was observed in a range of dexamethasone-resistant and dexamethasone-sensitive xenografts representative of B-ALL, T-ALL and Philadelphia chromosomepositive ALL. GCS-3 in combination with dexamethasone downregulated C-MYC and significantly upregulated BIM expression in a glucocorticoid-resistant ALL xenograft. The GCS-3/dexamethasone combination significantly increased binding of the glucocorticoid receptor to a novel BIM enhancer, which is associated with glucocorticoid sensitivity.

CONCLUSIONS: This study describes the potential of the novel glucocorticoid sensitiser, GCS-3, as a biological tool to interrogate glucocorticoid action and resistance.

British Journal of Cancer (2020) 122:1769-1781; https://doi.org/10.1038/s41416-020-0824-8

\section{BACKGROUND}

The introduction of multi-agent chemotherapy protocols in paediatric acute lymphoblastic leukaemia (ALL) has led to 5-year event-free survival rates of more than $85 \%$ and 5 -year overall survival rates approaching $90 \%$ in developed countries. ${ }^{1-4}$ However, due to the high incidence of paediatric ALL, it remains one of the most common causes of death from disease in children, and relapsed ALL has a similar incidence to rhabdomyosarcoma. ${ }^{5-7}$ Glucocorticoids (e.g. dexamethasone, prednisolone) are critical components of chemotherapy protocols in paediatric $A L L$, and response to glucocorticoid therapy is a major prognostic factor. ${ }^{8-10}$ Contemporary clinical trials based on the Berlin-Frankfurt-Munich (BFM) protocol include an initial week of glucocorticoid monotherapy, prior to multi-agent chemotherapy, where poor response is predictive of an inferior outcome. ${ }^{10-12}$ Acquired resistance to glucocorticoids is common at relapse, and is disparate compared with other chemotherapeutic agents used in the treatment of paediatric ALL. ${ }^{13,14}$ Although glucocorticoids can be extremely effective, the emergence of intrinsic and acquired resistance remains a significant barrier to cure paediatric ALL.

Glucocorticoids are steroid hormones that induce apoptosis in normal and malignant lymphoid cells. ${ }^{15,16}$ Glucocorticoids enter the cell through passive diffusion, where they bind to the glucocorticoid receptor (GR), a member of the nuclear receptor family of ligand-dependent transcription factors. ${ }^{15,16}$ Once activated, the GR translocates to the nucleus where it activates target genes by binding as a homodimer to specific palindromic DNA sequences, known as glucocorticoid response elements (GREs). ${ }^{15,16}$ We have previously demonstrated that dexamethasone resistance in ALL xenografts and patient samples occurred downstream of GRE binding, and that dexamethasone resistance was associated with failure to induce the proapoptotic protein BIM. ${ }^{17,18}$ We have found that the BIM gene is epigenetically silenced via deacetylation of histone $\mathrm{H} 3$ in dexamethasoneresistant ALL xenografts, and in two independent cohorts of chemo-resistant patient biopsy samples. ${ }^{19}$

Historically, little is known about the signalling pathways that regulate BIM expression after glucocorticoid treatment. Recent work in our laboratory has identified two novel signalling pathways involved in glucocorticoid-induced apoptosis of ALL cells. $^{20,21}$ In the first signalling pathway, the activated GR induces KLF13 expression by binding to its promoter. KLF13 inhibits SP1triggered $M Y B$ transcription, and $M Y B$ suppression leads to decreased expression of the anti-apoptotic protein, BCL-2.

${ }^{1}$ Children's Cancer Institute, School of Women's and Children's Health, UNSW Sydney, Sydney, NSW, Australia

Correspondence: Richard B. Lock (rlock@ccia.org.au)

Received: 27 September 2019 Revised: 5 February 2020 Accepted: 9 March 2020

Published online: 3 April 2020 
However, in dexamethasone-resistant ALL, treatment with glucocorticoids activates the GR, but KLF13 expression is not induced and apoptosis is inhibited. In the second signalling pathway, the activated GR binds directly to an intronic region in the BIM gene (BIM-IGR), triggering BIM expression, which results in apoptosis. In dexamethasone-resistant ALL, the activated GR cannot bind to the $B I M-I G R$ to trigger apoptosis. In a separate study, we have shown that in vivo dexamethasone treatment in a glucocorticoidsensitive ALL xenograft caused significant repression of the oncogene C-MYC. ${ }^{22}$

We have performed a 40,000 compound high-throughput screening (HTS) campaign to identify glucocorticoid sensitisers specifically designed to reverse dexamethasone resistance in the paediatric ALL xenograft, ALL-19. ${ }^{23}$ ALL-19 was selected for use in the screen as it exhibits robust and high-level dexamethasone resistance both ex vivo and in vivo, and is representative of the most common paediatric ALL subtype, B-ALL. ${ }^{24,25}$ The screen identified four lead dexamethasone sensitisers, which all contained a thioimidazoline moiety. ${ }^{26}$ We developed structure-activity relationships for 32 thioimidazoline-based compounds and identified 2-((4,5-dihydro- $1 \mathrm{H}$-imidazol-2-yl)thio)- $\mathrm{N}$ isopropyl- $N$-phenylacetamide (GCS-3) as the lead glucocorticoid sensitiser due to its superior ex vivo half-life in liver microsomes. ${ }^{26}$ In this study, we show that GCS-3 downregulates C-MYC and reverses $B I M$ repression through both signalling pathways in a glucocorticoid-resistant ALL xenograft. We demonstrate the applicability of GCS-3 as a biological tool to further elucidate the mechanisms of glucocorticoid resistance and the development of strategies to reverse resistance in paediatric ALL.

\section{METHODS}

Information on reagents is provided in the Supplementary Methods section.

Ex vivo culture of xenograft and non-leukaemic cells

The development and characterisation of a series of paediatric ALL xenografts derived from patient biopsies have been previously described. ${ }^{24,25}$ All assays were performed using authenticated stocks of xenograft cells. ${ }^{27}$ Human peripheral blood mononuclear cells (PBMCs) and $\mathrm{CD}_{3} 4^{+}$cells isolated from human cord blood were purchased (Lonza, VIC, Australia) or obtained from the Sydney Cord Blood Bank under approval of the Prince of Wales Hospital. Mononuclear cells were separated from cord blood by density gradient centrifugation (ELITech Australian and New Zealand, VIC, Australia) and $\mathrm{CD}_{3} 4^{+}$cells were isolated using magnetic beads and autoMACS separation (Miltenyi Biotec, NSW, Australia). Culture of $\mathrm{CD}_{3} 4^{+}$cells was carried out as previously described. ${ }^{28}$

For experiments using xenograft cells and PBMCs, cells were retrieved from cryostorage and resuspended in RPMI-1640 medium (Invitrogen Life Technologies, Gaithersburg, MD) supplemented with $10 \%$ foetal bovine serum (Invitrogen Life Technologies) (complete RPMI). Cells were centrifuged, aspirated, and washed with complete RPMI. The cells were resuspended in QBSF60 medium (Quality Biological, Gaithersburg, MD) supplemented with Flt-3 ligand (Amgen, Thousand Oaks, CA) (complete QBSF) at a cell concentration previously optimised for each xenograft/ peripheral blood mononuclear cell $\left(1-5 \times 10^{6}\right.$ cells per $\left.\mathrm{mL}\right)$. Viability was determined by the exclusion of $0.2 \%$ trypan blue (Sigma, NSW, Australia). For all experiments, cells were seeded and equilibrated overnight at $37^{\circ} \mathrm{C}, 5 \% \mathrm{CO}_{2}$ prior to drug treatment.

Cytotoxicity assays

In both single agent and combination cytotoxicity assays, $100 \mu \mathrm{L}$ of cell suspension was seeded in 96-well clear, U-bottom tissue culture-treated plates (In Vitro Technologies, VIC, Australia) at a cell concentration previously optimised. Plates were equilibrated overnight at $37^{\circ} \mathrm{C}, 5 \% \mathrm{CO}_{2}$ prior to drug treatment. Compounds were serially diluted in complete QBSF medium and added in triplicate wells. In combination cytotoxicity assays, cells were treated with GCS-3 and dexamethasone simultaneously at a fixed ratio of concentrations corresponding to $0.25,0.5,1,2$, and 4 times the half-maximal inhibitory concentration $\left({ } C_{50}\right)$ values for each drug independently and in combination. Where the $\mathrm{IC}_{50}$ values were $>10 \mu \mathrm{M}$, cells were treated with the following concentrations: 2.5, 5, 10, 20 and $40 \mu \mathrm{M}$, independently and in combination. Following $48 \mathrm{~h}$ incubation (unless otherwise stated) at $37^{\circ} \mathrm{C}, 5 \%$ $\mathrm{CO}_{2}$, cell viability was assessed by mitochondrial activity assay (Resazurin cell viability assay, $6 \mathrm{~h}$ incubation) or by flow cytometry (7-aminoactinomycin D and Annexin V; BD Biosciences, NSW, Australia). Cell viability was calculated as the percentage of untreated controls. $I C_{50}$ values were calculated from cumulative survival curves.

\section{Calculation of combination effect}

To determine whether GCS-3 was synergistic, additive or antagonistic with dexamethasone, the Bliss-Additivity (BA) model was used. ${ }^{29}$ Deviation from BA was calculated at each tested dose, where synergy is defined as $\geq 0.05$ and antagonism as $\leq-0.05$ (Table 1).

\section{Illumina gene expression and analysis}

Illumina gene expression arrays were performed by the Ramaciotti Centre (UNSW Sydney, NSW, Australia). Microarray studies were performed on complementary RNA samples using the Illumina Direct Hybridisation Gene Expression Array (Illumina, San Diego, CA). The studies were performed using HumanHT-12 v4 BeadChips (12 samples per chip) from Illumina. Samples were performed in duplicate and data were processed in $\mathrm{R}$ using Limma (a Bioconductor package). Data were normalised using neqc and bad quality probes were removed from further analysis. Differential expression analysis was performed to identify over-/underexpressed genes at 12 and $24 \mathrm{~h}$ (fold-change $\geq|2|, p<0.05$ ) when comparing treatment with dexamethasone, GCS-3 and GCS-3/ dexamethasone combination therapy against control. Significant genes were further analysed in KEGG (Kyoto Encyclopaedia of Genes and Genomes) pathway analysis and Gene Ontology (GO; Biological Processes, Cellular Components and Molecular Function) enrichment using DAVID. Functional analysis of the differentially expressed genes between dexamethasone and combination treatments was performed using gene set enrichment analysis [preRanked gene set enrichment analysis (GSEA), Broad Institute].

Real-time quantitative reverse transcription-PCR

Real-time quantitative reverse transcription-PCR (qRT-PCR) was performed using standard techniques. RNA was isolated using TRIzol (Invitrogen Life Technologies) and purified using the RNeasy RNA Isolation Kit (Qiagen, Germantown, MD). First-strand complementary DNA was synthesised using MMLV reverse transcriptase (Invitrogen Life Technologies). TaqMan primers and probes for KLF13 (Hs00429818_m1), BCL-2 (Hs00608023_m1), BIM (BCL2L11, Hs00708019_s1), GR (NR3C1, Hs00230813_m1), MYB (Hs00920556_m1) MYC (Hs00153408_m1) and EF1a (elongation factor 1a; Hs00265885_g1) were purchased from Invitrogen Life Technologies and RT-PCR was carried out in duplicate under

Table 1. Combination effect descriptions.

\begin{tabular}{ll}
\hline Deviation from BA & Description \\
\hline$\geq 0.05$ & Synergy \\
0.04 to -0.04 & Nearly additive \\
$\leq-0.05$ & Antagonism \\
\hline
\end{tabular}


Reversal of glucocorticoid resistance in paediatric acute lymphoblastic... C. E. Toscan et al.

Table 2. BIM-IGR, GILZ R1 and GILZ R2 primer sequences.

\begin{tabular}{lll}
\hline & Forward primer & Reverse primer \\
\hline BIM-IGR & CCAACTACTGGTGCCTCACA & CCCACCTGCCACTTCTGAAA \\
GILZ R1 & AGCCATGAACACCGAAATG & TCCAGCTTAACGGAAACCAC \\
GILZ R2 & ATGTGGTTTAACTGGGCCAC & ATATAGGAGGAGCCGGCTG
\end{tabular}

cycling conditions according to the manufacturer's instructions. EF1a was used as an internal control for each sample, where the primers and probe were optimised to not interfere with target gene amplification (primers EF1a forward, 5'-CTGAACCATCCAGG CCAAAT-3'; EF1a reverse, 5'-GCCGTGTGGCAATCCAAT-3'; probe, $5^{\prime}$-VIC-AGCGCCGGCTATGCCCCTG-TAMRA-3'). Target messenger RNA expression was normalised to EFla in each sample and fold differences were calculated by comparison with vehicle-treated controls using the $\Delta \Delta \mathrm{Ct}$ method.

Immunoblotting

Whole-cell lysates of ALL-19 xenograft cells were prepared by incubation with RIPA lysis buffer supplemented with Protease Inhibitor (Sigma). Nuclear and cytoplasmic cell lysates were prepared using the NE-PER Nuclear and Cytoplasmic Extraction Kit (Invitrogen Life Technologies). Protein concentration was determined by BCA assay using a bovine serum albumin standard (Invitrogen Life Technologies). The membranes were probed with primary antibodies: BIM, MYC, GR (Cell Signalling, Danvers, MA), actin, a-tubulin (Sigma), DNA topoisomerase I (Novus Biologicals, Centennial, CO). Secondary antibodies were horseradish peroxidase conjugates of either anti-mouse or anti-rabbit immunoglobulin G (IgG) (Sigma). The bound secondary antibody was detected by chemiluminescence and imaged using a VersaDoc Imaging System (Model 5000).

GR-DNA-binding ELISA

Nuclear cell lysates were assayed for GR-DNA-binding activity using the TransAM Transcription Factor ELISA (enzyme-linked immunosorbent assay) Kit (Active Motif, Carlsbad, CA). GR-DNAbinding activity was expressed relative to a HeLa-positive control nuclear lysate, prepared from HeLa cells treated with $100 \mathrm{nM}$ dexamethasone for $1 \mathrm{~h}$ (supplied in the kit).

\section{Chromatin immunoprecipitation}

Chromatin immunoprecipitation (ChIP) was carried out as previously described. ${ }^{20}$ Briefly, xenograft cells were treated with vehicle control, $1 \mu \mathrm{M}$ dexamethasone, $10 \mu \mathrm{M}$ GCS-3 or a combination of $1 \mu \mathrm{M}$ dexamethasone and $10 \mu \mathrm{M}$ GCS-3 for $8 \mathrm{~h}$ ex vivo, and fixed with $1 \%$ formaldehyde for $10 \mathrm{~min}$ at room temperature. Nuclei were extracted from fixed cells by $10 \mathrm{~min}$ incubation in lysis buffer $(0.2 \%$ NP40 in $10 \mathrm{mM}$ Tris buffer, $\mathrm{pH} 8.0)$, followed by centrifugation at $1250 \times g$ for $5 \mathrm{~min}$ at $4{ }^{\circ} \mathrm{C}$. Chromatin was fragmented using a Bioruptor sonicator (Diagenode SA, Belgium) on high power at $4{ }^{\circ} \mathrm{C}$ with $30 \mathrm{~s}$ on/off for $10 \mathrm{~min}$. Separate immunoprecipitates were produced using Ig raised against the GR (Cell Signalling) and processed according to the manufacturer's instructions. DNA from protein-associated complexes and corresponding input samples was recovered using phenol/chloroform/ isoamyl alcohol with phase lock gel tubes (5 Prime, Hilden, Germany). The ChIP DNA samples were assayed by SYBR-green real-time PCR using custom primers (Table 2) and the ABI7900 PCR instrument (Life Technologies, CA). The fold enrichment of ChIP DNA with target antibodies was normalised to IgG control (IgG from rabbit serum, Sigma).

Luciferase reporter assay

The luciferase reporter assay was performed using $\mathrm{pGL} 2 \mathrm{~B}$ vectors from Promega (Madison, WI). BIM promoter and IGR sequences
Table 3. Genomic location of BIM promoter and BIM-IGR.

\begin{tabular}{lll}
\hline Cloned sequences & Genomic location & Size (bp) \\
\hline BIM promoter & Chr2: 111,877,900-111,878,679 & 780 \\
BIM-IGR & Chr2: 111,914,645-111,915,877 & 1233 \\
\hline
\end{tabular}

were synthesised as double-stranded DNA (dsDNA) by Integrated DNA Technologies (Coralville, IA). The genomic location and size of dsDNA are listed in Table 3. The promoter dsDNA was inserted into $\mathrm{pGL} 2 \mathrm{~B}$ vector at the multiple cloning region $20 \mathrm{bp}$ upstream of the $5^{\prime}$ end of firefly luciferase gene, and the IGR dsDNA was inserted at $1 \mathrm{~kb}$ downstream of the $3^{\prime}$ end of the firefly luciferase gene. The cloned vector was linearised by Scal restriction enzyme, and a PGKNeo (Promega) vector was linearised by Hindlll. The two linearised vectors were co-transfected into Nalm6 cells and incubated at $37^{\circ} \mathrm{C}$ overnight. G418 (Geneticin, Sigma) was added to the transfected cells at $1 \mathrm{mg} / \mathrm{mL}$ and incubated for 7-10 days. The firefly luminescence was detected in the G418selected cells after $16 \mathrm{~h}$ treatment with vehicle control, $1 \mu \mathrm{M}$ dexamethasone, $10 \mu \mathrm{M}$ GCS-3 or a combination of $1 \mu \mathrm{M}$ dexamethasone and $10 \mu \mathrm{M}$ GCS-3 using the Bright-Glo ${ }^{\mathrm{TM}}$ Luciferase Assay System (Promega). Fold inductions were calculated by normalising to vehicle control.

\section{RESULTS}

Ex vivo sensitivity of ALL xenografts to dexamethasone correlates with patient outcome

The development and characterisation of paediatric ALL xenografts derived from patient biopsies have been previously described in detail. ${ }^{24,25}$ We assessed the ex vivo dexamethasone sensitivity of a panel of 20 ALL xenografts, which consisted of a range of $A L L$ subtypes, including: B-ALL, T-ALL, Philadelphia chromosome-positive $\mathrm{ALL}\left(\mathrm{Ph}^{+}-\mathrm{ALL}\right)$, mixed lineage leukaemiarearranged $(M L L r)$ and early T-cell precursor ALL (ETP-ALL). The ALL xenografts were established from patient samples taken at either diagnosis or relapse, and the current clinical status varies from alive in 1-3rd complete remission (CR1-3) to died of disease (DOD). Two distinct groups of dexamethasone-sensitive $\left(\mathrm{IC}_{50}<\right.$ $100 \mathrm{nM})$ and dexamethasone-resistant $\left(\mathrm{IC}_{50}>40 \mu \mathrm{M}\right)$ were observed (Supplementary Table S1). A significant correlation was observed between ex vivo dexamethasone efficacy $\left(\mathrm{IC}_{50}\right)$ and patient clinical status (CR1-3 or DOD) in the 19 ALL xenografts where clinical data were available (Supplementary Fig. S1). No significant correlations were observed between ex vivo dexamethasone sensitivity and ALL subtype or disease status at biopsy (data not shown). This finding highlights the clinical relevance of the ALL xenograft model in studying glucocorticoid resistance.

\section{GCS-3 is a specific glucocorticoid sensitiser}

The chemical structure of the novel glucocorticoid sensitiser GCS3 is shown in Fig. 1a, and its synthesis and characterisation have been reported previously. ${ }^{26}$ GCS-3 was identified from an HTS campaign to reverse dexamethasone resistance in the paediatric ALL xenograft, ALL-19, where compounds were added simultaneously. ${ }^{23}$ Modifying the timing of GCS-3 addition confirmed that dexamethasone sensitisation was maximal when GCS-3 and dexamethasone were administered simultaneously (Supplementary Fig. S2). All experiments henceforth have compounds added simultaneously unless otherwise stated.

Fixed-ratio combination cytotoxicity assays showed that GCS-3 was synergistic with dexamethasone or prednisolone against ALL19; hence, GCS-3 is a broad glucocorticoid sensitiser (Fig. 1b, c, Supplementary Table S2). Similar results were observed when the GCS-3/dexamethasone combination was tested against ALL-19 using a direct measure of cell viability (Fig. 1d, Supplementary 
a<smiles>CC(C)N(C(=O)CSC1=[NH+]CCN1)c1ccccc1</smiles>

$$
\begin{aligned}
& \rightarrow \text { Glucocorticoid } \\
& \rightarrow \text { GCS-3 } \\
& \rightarrow-\text { GCS-3 + glucocorticoid }
\end{aligned}
$$

C

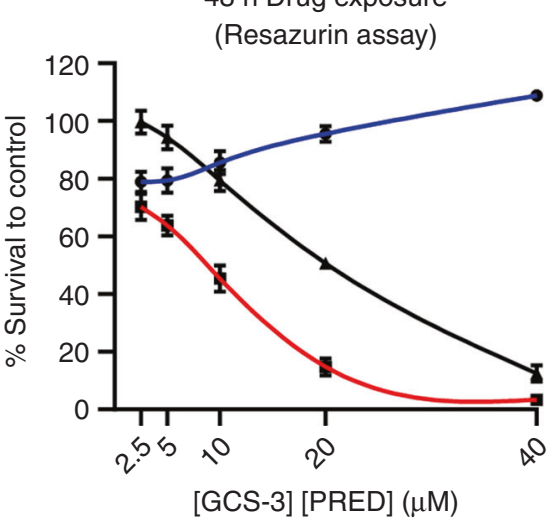

e $\quad 12 \mathrm{~h}$ Drug exposure, $36 \mathrm{~h}$ drug-free

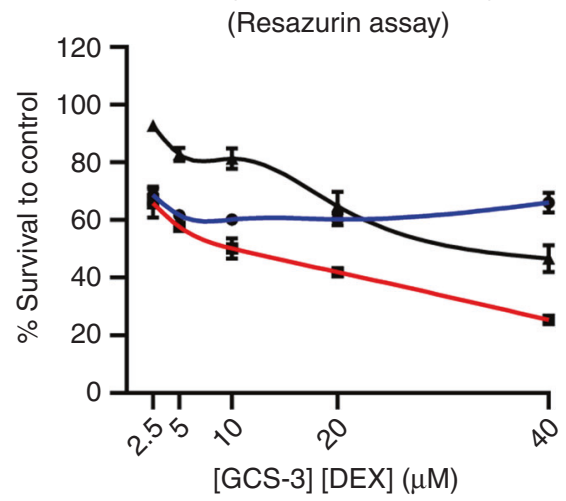

b

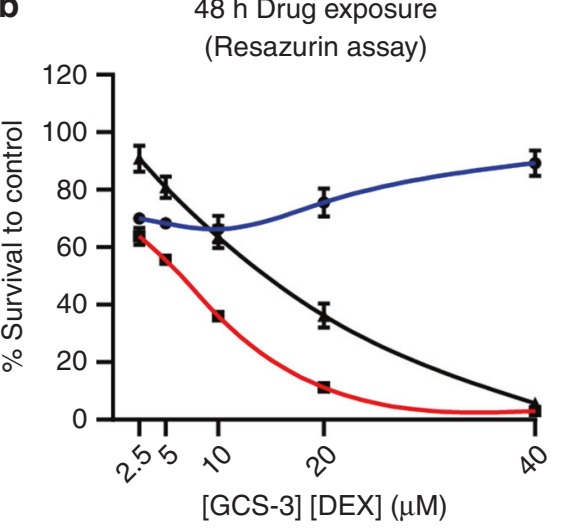

d

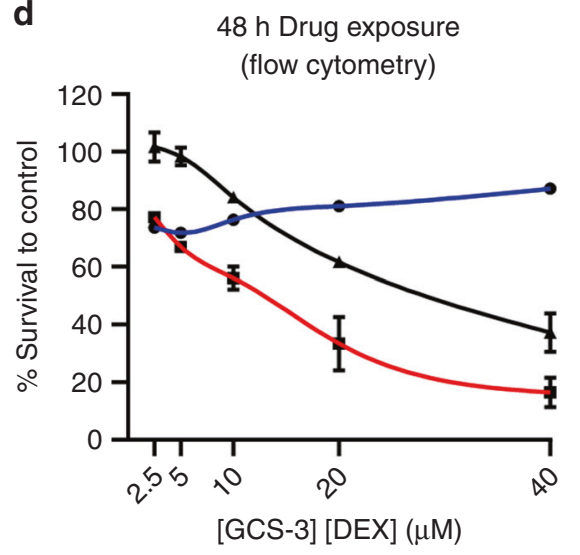

$\mathbf{f}$

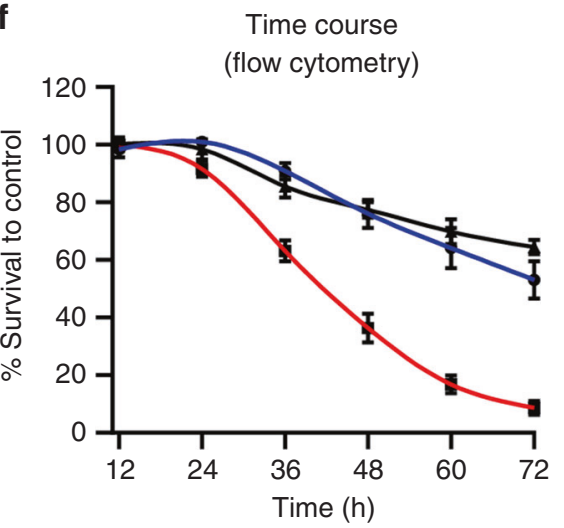

Fig. 1 Ex vivo efficacy of GCS-3 in combination with dexamethasone or prednisolone against ALL-19 xenograft cells. a Chemical structure of GCS-3, 2-((4,5-dihydro-1H-imidazol-2-yl)thio)- $N$-isopropyl- $N$-phenylacetamide. b-d ALL-19 xenograft cells were exposed to GCS-3, glucocorticoid or both in combination at a fixed ratio of concentrations for $48 \mathrm{~h}$, and cell viability was then assessed by Resazurin assay $(\mathbf{b}, \mathbf{c})$ or flow cytometry (d). e After $12 \mathrm{~h}$ drug incubation, drug-containing media were removed and cells were incubated in fresh media for 36 $\mathrm{h}$, and cell viability was assessed by Resazurin assay. $\mathbf{f}$ ALL-19 xenograft cells were treated with $10 \mu \mathrm{M} \mathrm{GCS}-3,10 \mu \mathrm{M}$ dexamethasone or both in combination. Cell viability was determined by flow cytometry at various time points up to $72 \mathrm{~h}$. Each data point represents the mean \pm SEM of at least three independent experiments.

Table S2). The action of GCS-3 is reversible as removal of GCS-3/ dexamethasone after $12 \mathrm{~h}$ incubation against ALL-19 resulted in loss of single agent and combination activity (Fig. 1e, Supplementary Table S2). A time-course experiment against ALL-19 showed that the combination caused a marked decrease in cell viability compared to the single agents, with $<10 \%$ viable cells remaining at $72 \mathrm{~h}$ (Fig. $1 \mathrm{f}$ ).

To determine the effect of GCS-3/dexamethasone on nonleukaemic cells, fixed-ratio combination cytotoxicity assays were performed on human PBMCs and human CD34 ${ }^{+}$cells. The GCS-3/ dexamethasone combination was not synergistic in normal human cells (Supplementary Figs. S3 and S4, Supplementary Table S3). To determine if GCS-3 is a specific glucocorticoid sensitiser, fixed-ratio combination cytotoxicity assays were performed with GCS-3 in combination with other classes of chemotherapeutics (daunorubicin, vincristine or cisplatin). GCS-3 was not synergistic in combination with all three chemotherapeutic drugs at every concentration tested in ALL-19 cells (Supplementary Fig. S5, Supplementary Table S4). This suggests that GCS-3 selectively restores glucocorticoid sensitivity. 
a

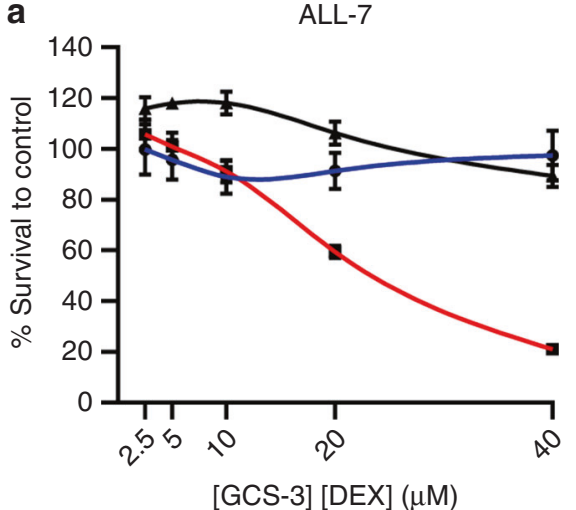

c

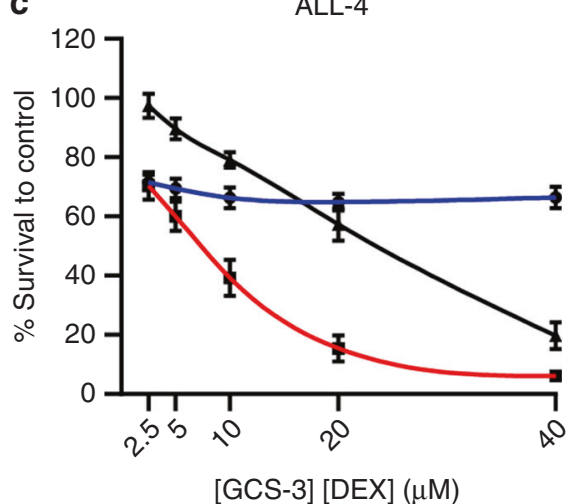

e

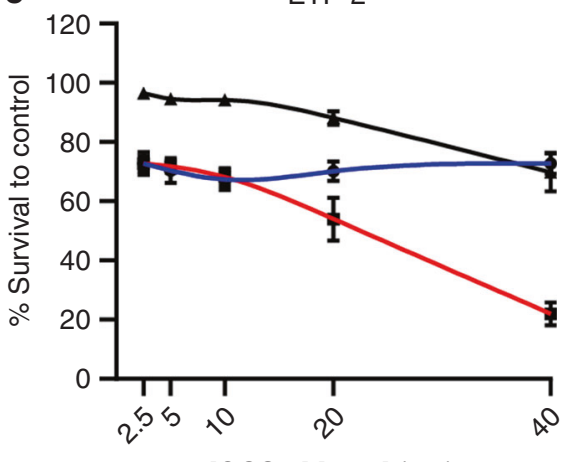

b
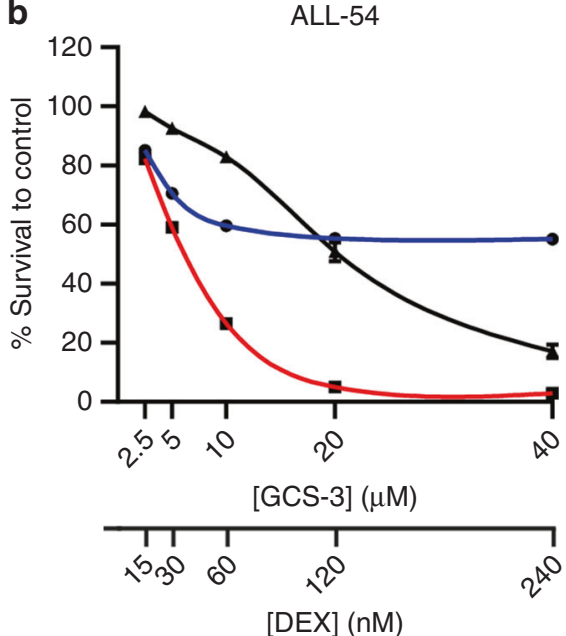

d

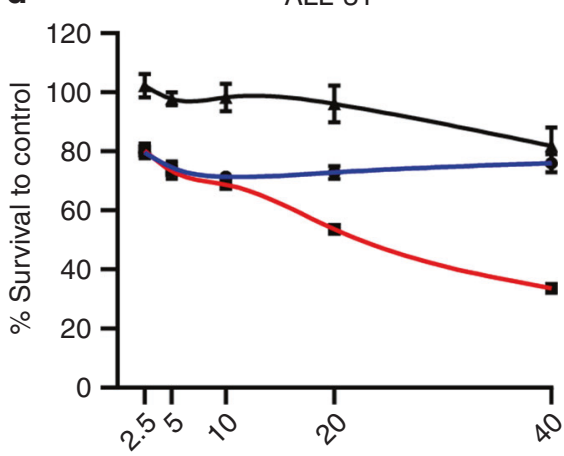

[GCS-3] [DEX] ( $\mu \mathrm{M})$

[GCS-3] [DEX] ( $\mu \mathrm{M})$

Fig. 2 Ex vivo efficacy of GCS-3 in combination with dexamethasone against ALL xenograft cells. ALL-7 (a), ALL-54 (b), ALL-4 (c), ALL-31 (d) and ETP-2 (e) xenograft cells were exposed to GCS-3, dexamethasone or both in combination at a fixed ratio of concentrations for $48 \mathrm{~h}$, and cell sensitivity was then assessed by Resazurin cytotoxicity assay. Each data point represents the mean \pm SEM of at least three independent experiments.

GCS-3 has broad applicability

To determine if GCS-3 showed broader applicability as a glucocorticoid sensitiser, fixed-ratio combination cytotoxicity assays were performed with dexamethasone against an additional 19 ALL xenografts (Fig. 2, Supplementary Fig. S6, Supplementary Table S5). Thirteen B-ALL xenografts including five dexamethasone-sensitive xenografts (ALL-54, ALL-17, ALL-55, ALL-56 and ALL-3) and eight dexamethasone-resistant xenografts (ALL-19, ALL-2, ALL-50, ALL-7, ALL-88, ALL-84, ALL-4 and MLL-5) were tested. The greatest sensitising effect was observed in ALL-7 (Fig. 2a), which is a high-risk subtype with a TCF3-HLF fusion gene, where the highest concentration of GCS-3/dexamethasone caused $66 \%$ greater cytotoxicity than the calculated additive effect. In the high-risk $\mathrm{Ph}^{+}$B-ALL subtype, sensitising effects were observed in the highly dexamethasone-resistant xenograft, ALL-4 (Fig. 2c). In summary, GCS-3 sensitised 5 out of 13 B-ALL xenografts to dexamethasone, including dexamethasone-resistant and dexamethasone-sensitive xenografts.

Seven T-ALL xenografts including three dexamethasonesensitive xenografts (ALL-43, ALL-16, ETP-1) and four dexamethasone-resistant xenografts (ALL-31, ALL-32, ETP-2, ETP3) were tested. The greatest sensitising effect was observed in ALL-31 (Fig. 2d), where the highest concentration of GCS-3/ dexamethasone caused $29 \%$ greater cytotoxicity than the calculated additive effect. In the high-risk ETP-ALL subtype, sensitising effects were observed in the dexamethasoneresistant xenograft, ETP-2 (Fig. 2e). In summary, GCS-3 sensitised two out of seven T-ALL xenografts to dexamethasone. GCS-3 showed broad applicability on multiple ALL subtypes to restore or enhance glucocorticoid sensitivity. Overall, synergy was observed 
in 6 out of 12 dexamethasone-resistant and 1 out of 8 dexamethasone-sensitive xenografts.

GCS-3 requires a functional GR to induce caspase-dependent apoptosis

To determine if GCS-3 required a functional GR to sensitise ALL cells to glucocorticoids, GCS-3 in combination with dexamethasone was assessed in two glucocorticoid-resistant BCP-ALL cell lines, HAL-01 and UoC-B1. Both cell lines are highly dexamethasoneresistant, but unlike glucocorticoid-resistant xenografts and patient biopsies, both cell lines express a dysfunctional GR. ${ }^{18}$ The GCS-3/ dexamethasone combination was nearly additive in both cell lines (Fig. 3a, b, Supplementary Table S6). To determine if GCS-3 was able to sensitise proliferating ALL cells to glucocorticoids, the GCS3/dexamethasone combination was tested in the glucocorticoidresistant B-ALL cell line, ALL-4CL. The ALL- $4 C L$ is derived from the ALL-4 xenograft and maintains resistance to glucocorticoids while expressing a functional GR. ${ }^{18}$ As seen with the ALL-4 xenograft, the GCS-3/dexamethasone combination was synergistic in ALL-4CL (Fig. 3c, Supplementary Table S6). Although GCS-3 requires a functional GR to sensitise ALL cells to glucocorticoids, the addition of GCS-3 did not enhance dexamethasone-induced GR translocation to the nucleus or GR-DNA binding in ALL-19 cells (Fig. 3d, e, respectively, Supplementary Fig. S7).

Both glucocorticoids and vincristine induce cell death in lymphoid cells via caspase-dependent apoptosis. ${ }^{30}$ To determine whether this cell death mechanism was activated by the GCS-3/ dexamethasone combination in ALL-19 cells, the effect of the pancaspase inhibitor QVD-OPh on the combination treatment was assessed. ${ }^{31}$ As the glucocorticoid-resistant xenograft ALL-19 is vincristine sensitive, vincristine was used as a positive control (Supplementary Fig. S8). Pre-incubation with QVD-OPh significantly increased the viability of ALL-19 cells treated with the combination (Fig. 3f). Therefore, the combination of GCS-3 and dexamethasone induces caspase-dependent apoptosis in ALL-19 xenograft cells and this effect can be inhibited using the pancaspase inhibitor, QVD-OPh.

\section{GCS-3 downregulates C-MYC expression}

To gain insight into the mechanism of action of GCS-3 in combination with dexamethasone, microarray analysis of gene expression was performed on ALL-19 cells treated with vehicle, GCS-3, dexamethasone or the combination for 12 or $24 \mathrm{~h}$ (Supplementary Fig. S9). Unsupervised hierarchical clustering demonstrated that there are few differences in the expression profile between GCS-3 and the vehicle at either time point, which was confirmed with differential expression analysis (Supplementary Table S7, Supplementary Fig. S10). Treatment with the combination of GCS-3 and dexamethasone caused the largest change in the gene expression profile of ALL-19 cells, with 1049 genes differentially expressed after $24 \mathrm{~h}$ treatment $(p<0.05$, FC $\geq|2|$; Supplementary Table S7).

To identify genes induced or repressed by GCS-3 in the presence of dexamethasone, differential gene expression was performed between the dexamethasone and combination treated groups. The 50 most differentially expressed genes after 12 and $24 \mathrm{~h}$ treatment are presented in Fig. $4 \mathrm{a}, \mathrm{b}$. C-MYC was one of the top 25 downregulated genes in the combination group compared to either single agent (Fig. 4a, b). This was confirmed by PCR and immunoblotting, where downregulation of C-MYC by the GCS-3/ dexamethasone combination was 2.0-fold greater than GCS-3 alone and 4.1 -fold greater than dexamethasone alone at $24 \mathrm{~h}$ (Fig. 4c, d, Supplementary Fig. S11).

GO analysis of the genes downregulated by GCS-3 in the presence of dexamethasone clustered into key biological processes and molecular functions that involved C-MYC, such as gene transcription (Supplementary Fig. S12A, B). GSEA was performed on the differentially expressed genes between dexamethasone and the combination treated groups at $24 \mathrm{~h}$ to determine whether genes induced and repressed by GCS-3 in the presence of dexamethasone are significantly concordant with published gene sets. The gene sets generated by Rhein et al. ${ }^{32}$ depict the changes in gene expression that occurred in ALL patients upon treatment with glucocorticoids in vivo. Genome-wide expression analysis was performed on blasts from $18 \mathrm{~B}$-ALL patients at days 0 and 8 , after prednisone treatment. GSEA revealed that genes upregulated/downregulated by GCS-3 in the presence of dexamethasone in ALL-19 cells were highly enriched for genes upregulated/ downregulated after glucocorticoid treatment in B-ALL patients (Supplementary Fig. S12C, D). These results show that the gene expression changes caused by GCS-3 in the presence of dexamethasone in ALL-19 cells are relevant to what is observed by glucocorticoid treatment in a clinical setting.

\section{GCS-3 restores BIM expression}

Recent work in our laboratory has identified two novel signalling pathways involved in glucocorticoid-induced apoptosis in ALL cells, and both centre on the opposing regulation of the proapoptotic gene, BIM, and the anti-apoptotic gene, BCL-2. ${ }^{20}$ GCS-3 was utilised to determine whether these two novel signalling pathways can be reactivated in ALL-19 cells. The glucocorticoid-induced apoptotic response in lymphoid cells is mediated through the GR. Microarray and PCR analysis of GR expression after 12 and $24 \mathrm{~h}$ treatment showed that the GCS-3/ dexamethasone combination did not reverse the dexamethasoneinduced downregulation of $G R$ expression (Fig. 5a, b). In glucocorticoid-sensitive ALL cells, treatment with glucocorticoids activates the $G R$, which up-regulates KLF13 expression, which is abrogated in glucocorticoid-resistant ALL. ${ }^{20}$ The GCS-3/dexamethasone combination significantly increased KLF13 expression compared to either single agent at $24 \mathrm{~h}$ (Fig. 5a, c). In glucocorticoid-sensitive ALL cells KLF13 displaces the MYB activator, SP1, and represses MYB expression. The GCS-3/dexamethasone combination further downregulated $M Y B$ expression compared to either single agent at $24 \mathrm{~h}$ (Fig. 5a, d). In glucocorticoid-sensitive ALL cells, MYB suppression leads to decreased expression of anti-apoptotic $B C L-2$. The GCS-3/dexamethasone combination significantly decreased $B C L-2$ expression by 3.9-fold compared to GCS-3 alone and 2.1-fold compared to dexamethasone alone at $24 \mathrm{~h}$ (Fig. 5a, e). In glucocorticoidsensitive ALL cells, $B C L-2$ suppression allows $B A X$-mediated apoptosis. The GCS-3/dexamethasone combination significantly increased BIM expression by 6.6-fold compared to GCS-3 alone and 2.4-fold compared to dexamethasone alone at $24 \mathrm{~h}$ (Fig. 5a, f, g, Supplementary Fig. S13).

The activated GR can also trigger BIM expression by binding to a $B I M-I G R$, leading to BAX-mediated apoptosis. Conventional ChIP analysis showed that the GCS-3/dexamethasone combination treatment increased binding of the GR at the BIM-IGR by 9.2 -fold compared to GCS-3 alone and 2.0-fold compared to dexamethasone alone (Fig. 6a). The GCS-3/dexamethasone combination also increased binding of the GR to GILZ, which is a primary target of the GR but is not directly involved in apoptosis (Supplementary Fig. S14). When the Nalm6 cell line was stably transduced with a BIM promoter-reporter construct, ${ }_{1}^{20}$ the GCS-3/dexamethasone combination significantly increased luciferase expression when compared to either single agent alone (Fig. 6b). In summary, GCS3 enhanced dexamethasone-induced binding of the GR to the $B I M-I G R$, which significantly increased BIM promoter activity.

BIM upregulation correlates with GCS-3/dexamethasone efficacy Upon dexamethasone treatment the GR antagonist, RU486, allows GR translocation to the nucleus but inhibits C-MYC suppression. ${ }^{33}$ To determine whether C-MYC repression was critical for GCS-3/ dexamethasone combination efficacy, the effect of RU486 on the combination treatment was assessed. Pre-incubation with RU486 
a

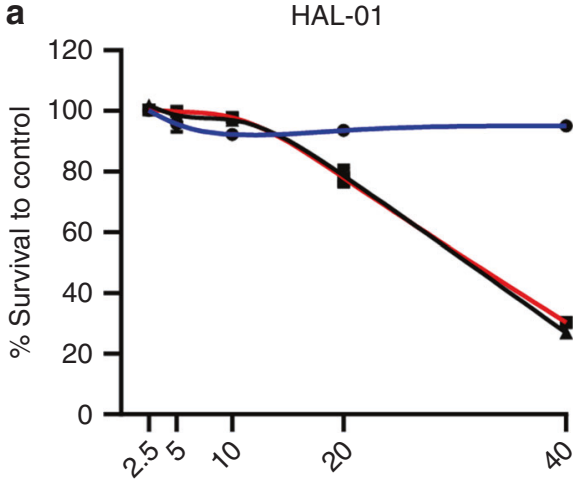

[GCS-3] [DEX] $(\mu \mathrm{M})$

C

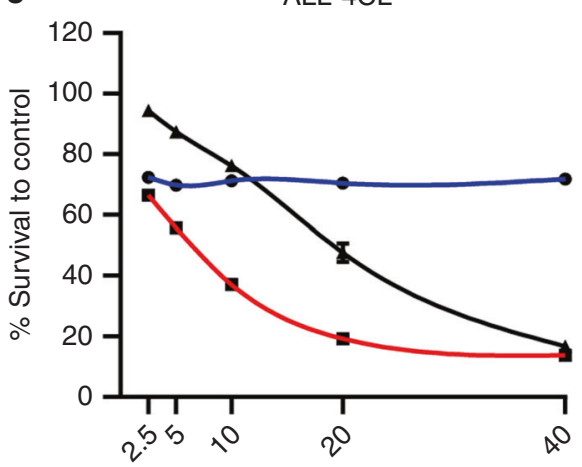

[GCS-3] [DEX] ( $\mu \mathrm{M})$

$\rightarrow$ DEX

$\mp$ GCS-3

GCS-3 + DEX

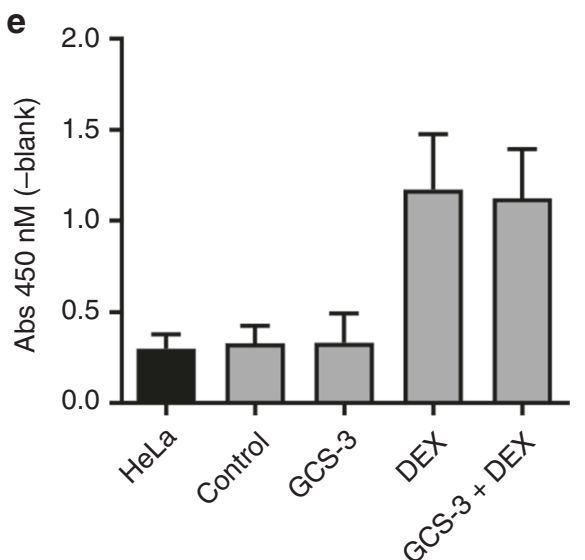

b

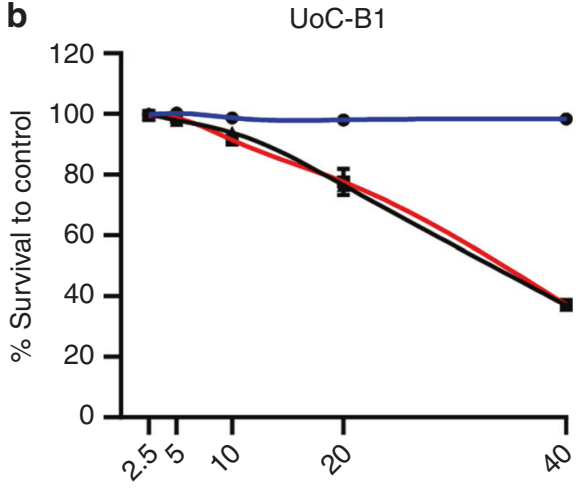

[GCS-3] [DEX] $(\mu \mathrm{M})$

d

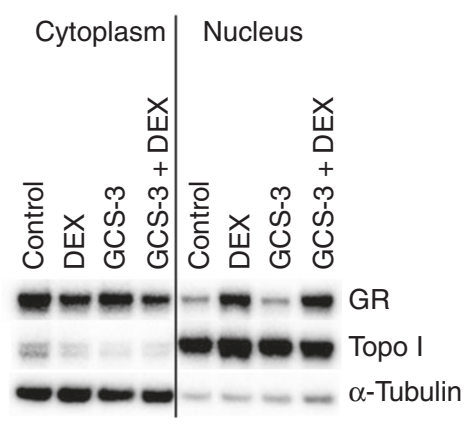

f

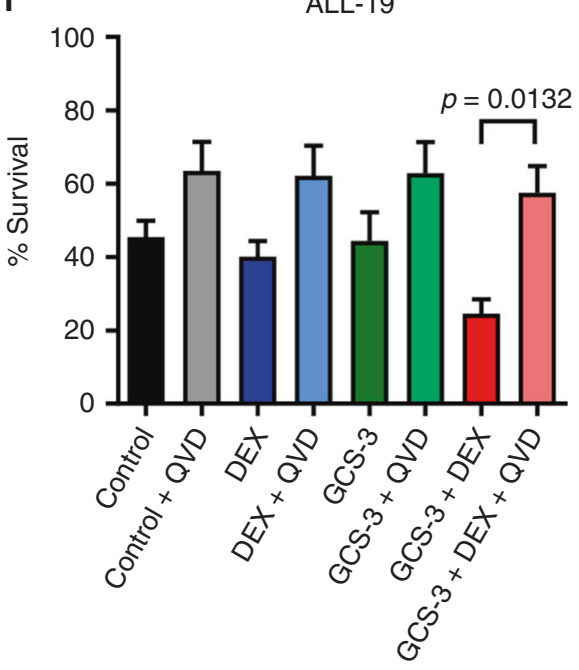

Fig. 3 GCS-3 requires a functional GR to induce caspase-dependent apoptosis. HAL-01 (a), UoC-B1 (b) or ALL-4CL (c) cells were exposed to GCS-3, dexamethasone or both in combination at a fixed ratio of concentrations for $48 \mathrm{~h}$, and cell sensitivity was then assessed by Resazurin cytotoxicity assay. Each data point represents the mean \pm SEM of at least three independent experiments. d, e ALL-19 xenograft cells were treated with $10 \mu \mathrm{M}$ GCS-3 and $1 \mu \mathrm{M}$ dexamethasone (DEX) for $1 \mathrm{~h}$ before separation into nuclear and cytoplasmic fractions. $\mathbf{d}$ Equal amounts of protein $(10 \mu \mathrm{g})$ from each fraction were immunoblotted for GR, Topo I (nuclear loading control) and $\alpha$-tubulin (cytoplasm loading control). e Dexamethasone-induced binding of the GR to a GRE motif was assessed using a DNA-binding ELISA, with equal amounts of nuclear lysates and HeLa control lysate $(5 \mu \mathrm{g})$. The OD $450 \mathrm{~nm}$ of each sample minus blank is shown. Each data point represents the mean \pm SEM of three independent experiments. f ALL-19 xenograft cells were pre-treated with $10 \mu \mathrm{M}$ QVD-OPh (QVD) or vehicle control for $2 \mathrm{~h}$. Cells were then exposed to $10 \mu \mathrm{M} \mathrm{GCS}-3,10 \mu \mathrm{M}$ dexamethasone (DEX) or both for $48 \mathrm{~h}$ and cell sensitivity was assessed by flow cytometry. Each data point represents the mean \pm SEM of four independent experiments. Significance was calculated using the unpaired $t$ test with Welch's correction. 


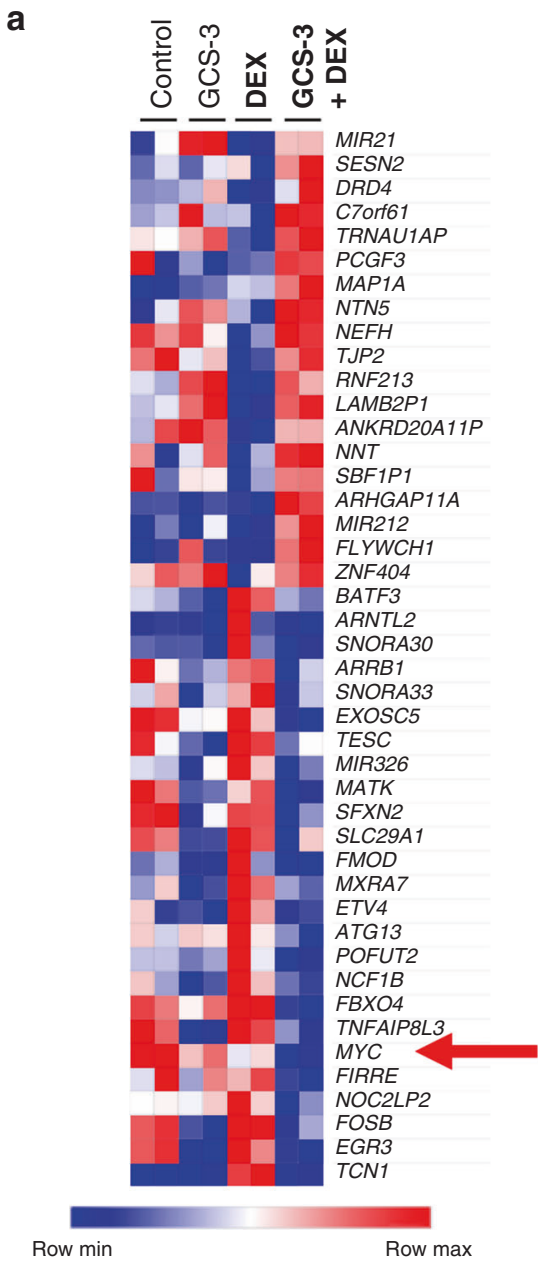

b
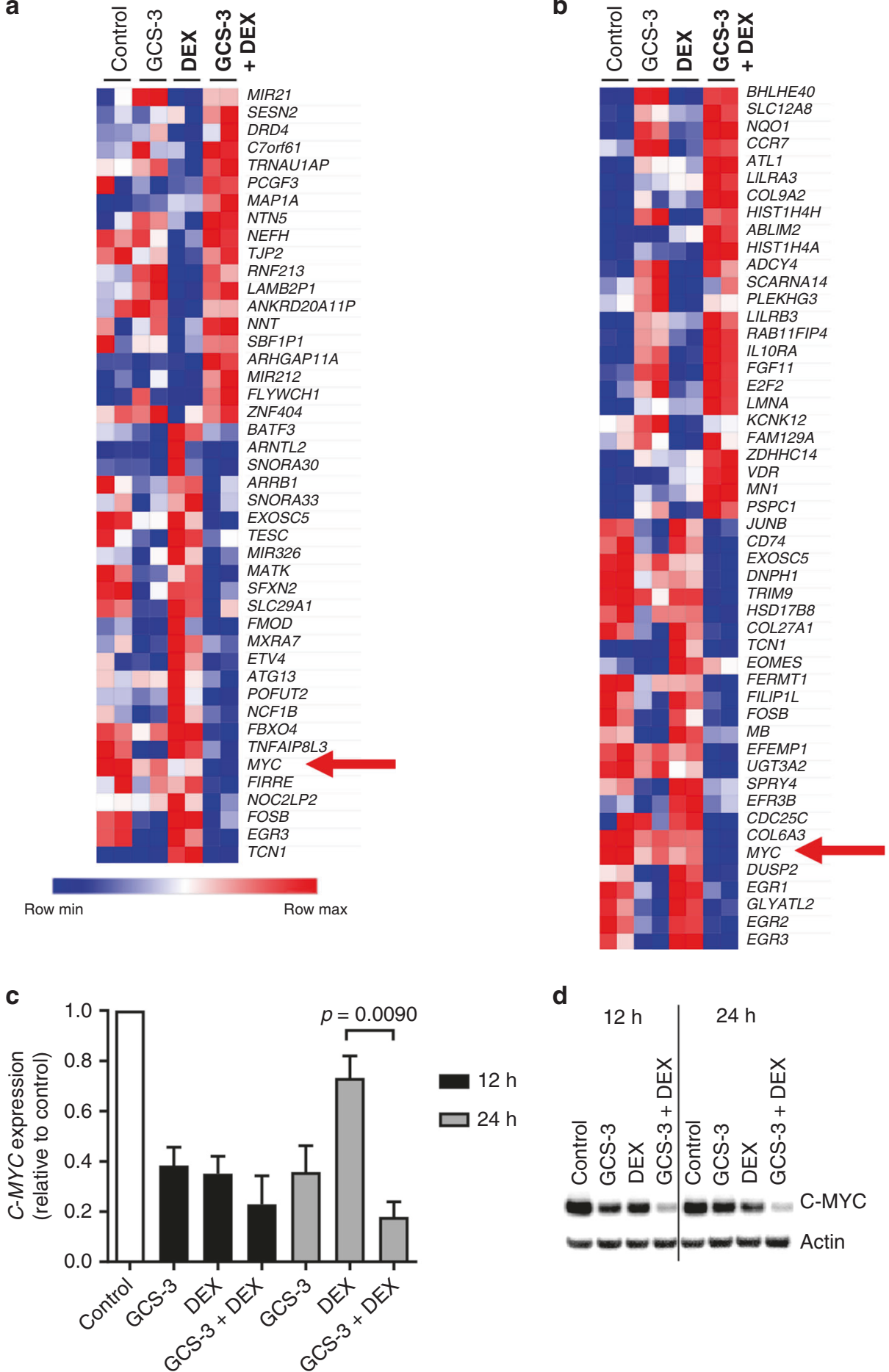

Fig. 4 Effects of GCS-3 on dexamethasone-induced gene expression changes. ALL-19 cells were treated with $10 \mu \mathrm{M}$ dexamethasone (DEX), $10 \mu \mathrm{M}$ GCS-3 or both in combination and gene expression profiling was performed. The top differentially expressed genes between the dexamethasone and combination treatment groups are shown after $12 \mathrm{~h}$ (a) and $24 \mathrm{~h}$ (b). Expression levels were normalised for each gene, where the mean is 0, higher than the mean are shown in red and lower in blue. c C-MYC mRNA expression was analysed by qRT-PCR and calculated relative to the 12 and $24 \mathrm{~h}$ vehicle-treated controls. Each data point represents the mean \pm SEM of three independent experiment. Significance was calculated using the unpaired $t$ test with Welch's correction. d C-MYC protein expression was analysed after 12 and $24 \mathrm{~h}$ treatment by immunoblotting and a representative blot is shown.

increased the viability of ALL-19 cells treated with dexamethasone alone, and significantly abrogated the cytotoxic effects of the GCS3/dexamethasone combination (Fig. 6c). Therefore, the cytotoxic effects of dexamethasone and the GCS-3/dexamethasone combination on ALL-19 cells are GR dependent.
While pre-incubation with RU486 had no effect on C-MYC expression of the control, GCS-3 and combination treated ALL19 cells, it did significantly increase C-MYC expression of the dexamethasone-treated ALL-19 cells (Fig. 6d). Therefore, dexamethasone and GCS-3 downregulate C-MYC via GR-dependent 

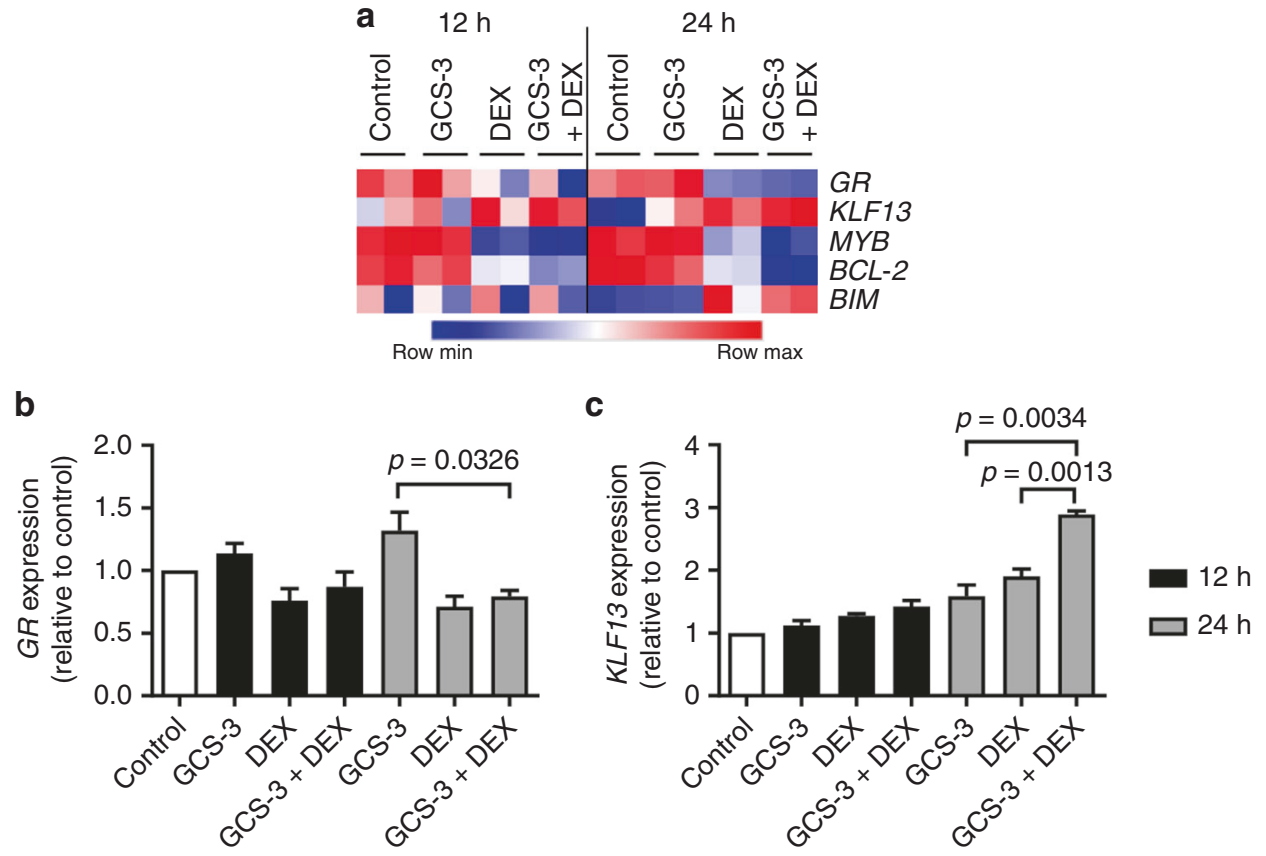

d

e
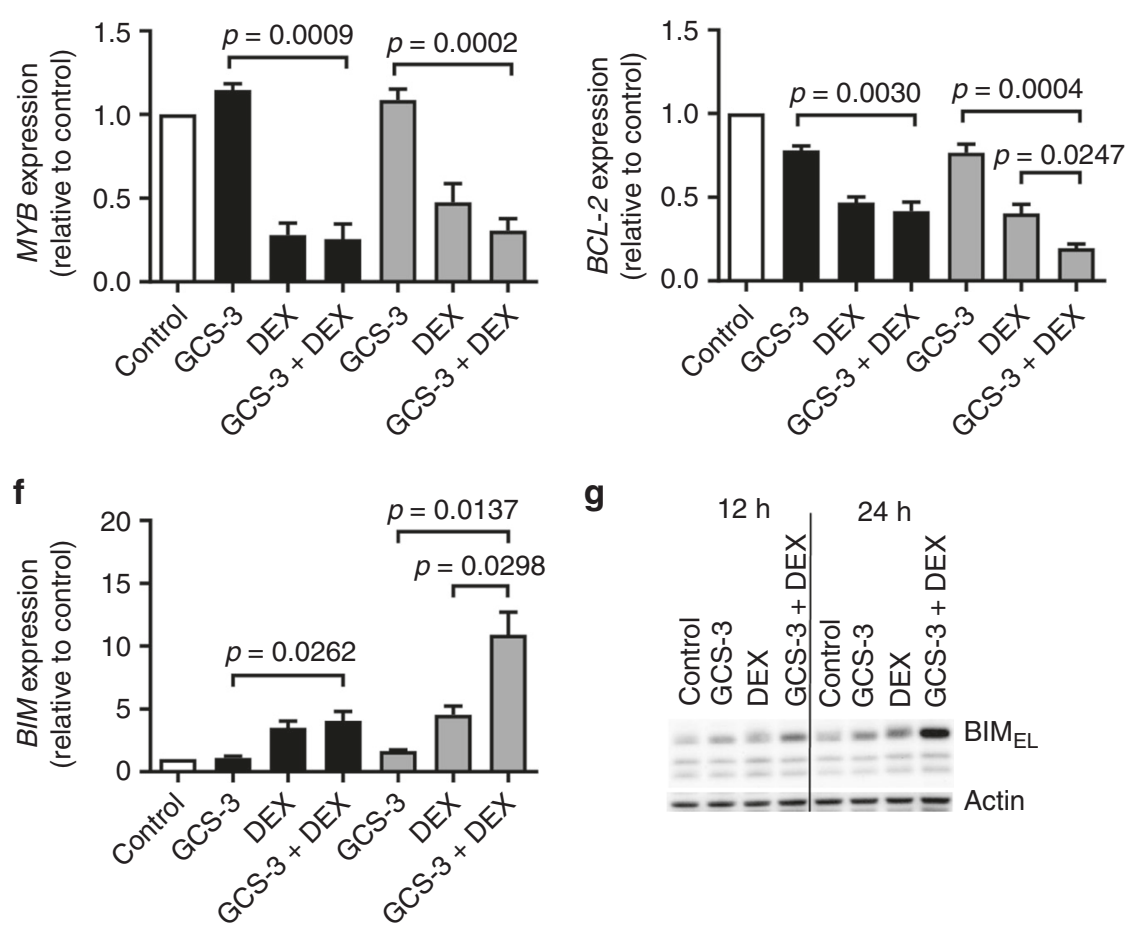

Fig. 5 Expression levels of candidate genes in ALL-19 cells. a Microarray analysis of the effects of $10 \mu \mathrm{M}$ GCS-3, $10 \mu \mathrm{M}$ dexamethasone and the combination on gene expression in ALL-19 cells. Two biological replicates were analysed at 12 and $24 \mathrm{~h}$ post treatment, where red represents high and blue low gene expression. GR (b), KLF13 (c), MYB (d), BCL-2 (e) and BIM (f) mRNA expression was analysed by qRT-PCR and calculated relative to the 12 and $24 \mathrm{~h}$ vehicle-treated controls. Each data point represents the mean \pm SEM of four independent experiments. Significance was calculated using the unpaired $t$ test with Welch's correction. g BIM protein expression was analysed after 12 and $24 \mathrm{~h}$ treatment by immunoblotting and a representative blot is shown.

and GR-independent pathways, respectively. Finally, GCS-3 as a single agent had no effect on BIM expression, but in combination with dexamethasone caused a significant increase (Fig. 6e). Notably, RU486 significantly suppressed the marked induction of BIM following treatment with the GCS-3/dexamethasone combination (Fig. 6e), consistent with its ability to reverse the cytotoxic effects of the combination (Fig. 6c). This was also observed with the dexamethasone-sensitive xenograft, ALL54 (Supplementary Fig. S15). In summary, RU486 inhibited GCS-3/dexamethasone combination cytotoxicity and BIM upregulation with no effect on C-MYC expression, indicating that only BIM upregulation is required for the cytotoxicity of the GCS-3/dexamethasone combination against ALL-19 and ALL-54 cells. 


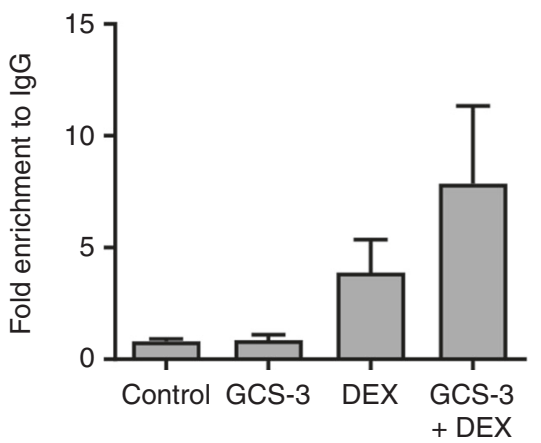

C

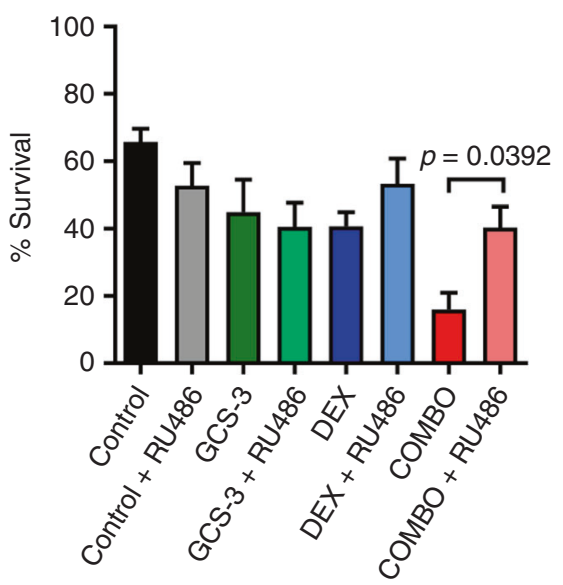

e

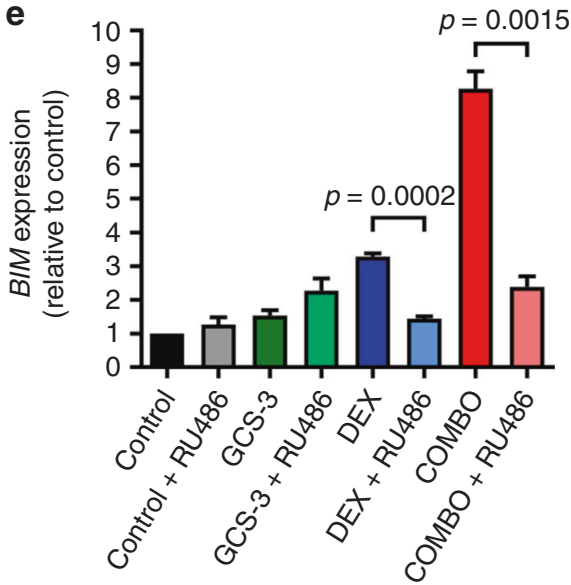

b

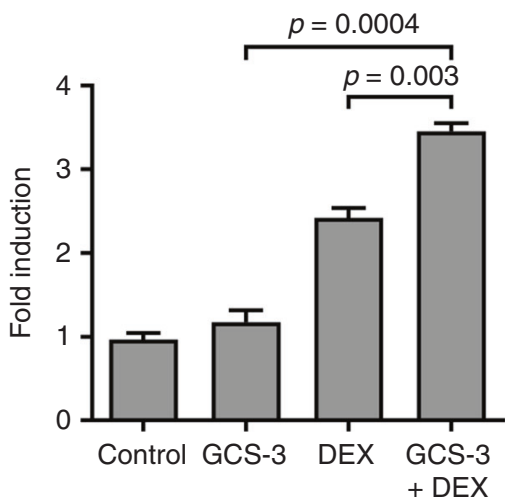

d

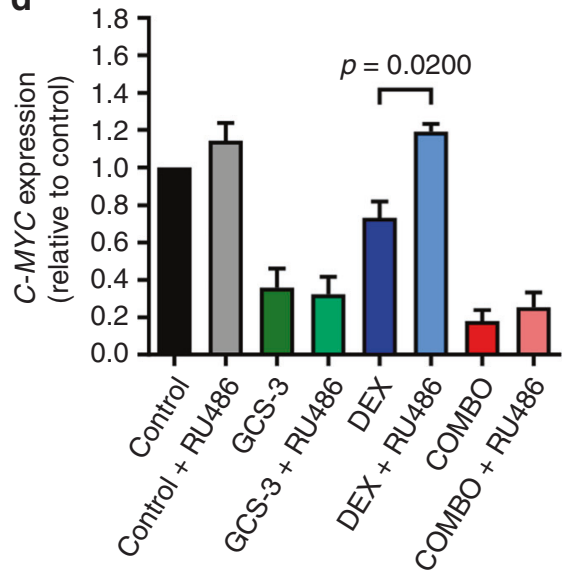

Fig. 6 BIM upregulation correlates with GCS-3/dexamethasone efficacy. a ALL-19 xenograft cells were treated with $10 \mu M$ dexamethasone, $10 \mu \mathrm{M}$ GCS-3 or both in combination for $8 \mathrm{~h}$. Conventional ChIP of GR binding at the BIM-IGR, fold change was calculated relative to the IgG control. b Nalm6 cells that were stably transduced with a BIM promoter-reporter construct were treated with $1 \mu \mathrm{M}$ dexamethasone, $10 \mu \mathrm{M}$ GCS-3 or both in combination for $16 \mathrm{~h}$. Fold change in luciferase induction was calculated. c-e ALL-19 cells were pre-treated with $1 \mu \mathrm{M}$ RU486, then treated with $10 \mu \mathrm{M} \mathrm{GSC}-3,10 \mu \mathrm{M}$ dexamethasone and the combination for $24 \mathrm{~h}$ (qRT-PCR) or $48 \mathrm{~h}$ (cell sensitivity). c Cell sensitivity was assessed by flow cytometry. d C-MYC and e BIM mRNA expression was analysed by qRT-PCR and calculated relative to the control. Each data point represents the mean \pm SEM of three independent experiments. Significance was calculated using the unpaired $t$ test with Welch's correction.

\section{DISCUSSION}

Many drug classes have shown the potential to reverse glucocorticoid resistance in $\mathrm{ALL}$, including histone deacetylase (HDAC), PI3K/AKT, mTOR, Pan-BCL-2, NOTCH, glycolysis, and cholesterol inhibitors. ${ }^{19,34-47}$ With the exception of J9, which was identified from an HTS assay against the T-ALL cell line, CUTLL1, none of these drugs were specifically developed as glucocorticoid sensitisers. ${ }^{48}$ We have previously tested $J 9$ in a panel of dexamethasone-resistant and dexamethasone-sensitive ALL xenografts and observed no dexamethasone-sensitising effect. ${ }^{26}$ These conflicting results are likely to be due to the experimental models employed as ALL xenografts are not passaged in vitro and harvested cells remain highly representative of the cell and molecular characteristics of the primary patient sample. ${ }^{24,25,49}$ 
The novel glucocorticoid sensitiser, GCS-3, was identified from an unbiased HTS campaign against the B-ALL xenograft, ALL$19 .^{23,26}$ GCS-3 was synergistic with dexamethasone in 7/20 ALL xenografts, which included both B-, T-, ETP- and $\mathrm{Ph}^{+}$ALL subtypes and glucocorticoid-resistant and glucocorticoid-sensitive ALL xenografts. This was an impressive finding as a number of glucocorticoid sensitisers are specific to a particular subtype of $A L L$, such as the $\gamma$-secretase inhibitor DBZ, which specifically sensitises glucocorticoid-resistant T-ALL with activated NOTCH1 mutations. ${ }^{44}$ Glucocorticoid use is associated with a number of side effects such as infection, osteonecrosis, psychosis and myopathy. ${ }^{50-54}$ Therefore, if GCS-3 is able to potentiate the effects of glucocorticoids in glucocorticoid-sensitive ALL, as seen with ALL-54, lower doses of glucocorticoids may be administered, which will reduce side effects.

As a prelude to testing the GCS-3/dexamethasone combination in vivo, the maximum-tolerated dose of GCS-3 was determined in naive NSG mice. A pharmacokinetic study in naive NSG mice revealed that there was insufficient GCS-3 in the blood plasma to warrant further investigation in vivo. Although GCS-3 requires further development prior to in vivo testing, it is promising that synergy was not observed with GCS-3/dexamethasone in normal, human cells. While the precise mechanism of GCS-3 action requires further delineation, this study presents several interesting findings. GCS-3 is a specific glucocorticoid sensitiser with no sensitising effect observed when combined with vincristine, daunorubicin or cisplatin. While most glucocorticoid sensitisers are also glucocorticoid specific, Obatoclax has been shown to resensitise drug-resistant primary ALL cells to daunorubicin, vincristine and cytarabine, as well as dexamethasone. ${ }^{43}$ GCS-3 requires a functional GR to sensitise cells to glucocorticoids, but when combined with dexamethasone did not increase $G R$ expression. Therefore, the mechanism of GCS-3 is different to the glucocorticoid sensitiser J9, which reverses dexamethasone resistance by upregulating $G R$ expression. ${ }^{48}$

A somewhat surprising finding was that GCS-3 exerted maximal sensitising effect when administered simultaneously with dexamethasone. It is therefore unlikely that GCS-3 is an epigenetic modifier, as pre-treatment would be expected to enhance efficacy with dexamethasone, as observed with the HDAC inhibitor vorinostat. ${ }^{19}$ Microarray analysis of gene expression identified $C$ MYC as one of the most significantly downregulated genes between the control and combination treated groups, and the dexamethasone- and combination treated groups. This was confirmed by PCR and immunoblotting, which showed that the GCS-3/dexamethasone combination caused a significant decrease in C-MYC expression. This is a notable finding as multiple studies have shown that glucocorticoid treatment in ALL represses C-MYC expression, and glucocorticoid resistance is associated with C-MYC over-expression. ${ }^{22,55-58}$

Another promising finding from this study was that the GCS-3/ dexamethasone combination significantly upregulated the expression of proapoptotic gene BIM compared to both single agents, which was confirmed by PCR and immunoblotting. Gene expression studies consistently show that BIM is upregulated by glucocorticoids in glucocorticoid-sensitive ALL samples. $55,56,59-61$ Our laboratory has shown that glucocorticoid resistance in ALL was associated with failure to induce BIM upon glucocorticoid treatment. ${ }^{1,18}$ Therefore, the combination of GCS-3 and dexamethasone induces gene expression changes in glucocorticoidresistant ALL-19 cells, which are observed upon glucocorticoid treatment in glucocorticoid-sensitive ALL cells.

Previous work in our laboratory has identified two novel signalling pathways involved in glucocorticoid-induced apoptosis in ALL cells, and both centre on the opposing regulation of the proapoptotic gene, $B I M$, and the anti-apoptotic gene, $B C L-2 .^{20}$ The GCS-3/dexamethasone combination was able to enhance both
$K L F 13-$ mediated $B C L-2$ repression and increase $G R$ binding to the $B I M-I G R$, which directly triggers BIM expression.

There are several studies that link C-MYC and BIM expression. A study performed in T-ALL cell lines and treatment-resistant patient samples showed that BIM is repressed downstream of C-MYC activation, and that BIM upregulation and apoptosis could be restored by treatment with C-MYC or PI3K-AKT pathway inhibitors. ${ }^{62}$ A study performed in the colon cancer cell line, HCT116, showed that genes encoding the $\mathrm{BH} 3$-only proteins NOXA and BIM are direct targets of $C-M Y C{ }^{63}$ Interestingly, that study showed that $C-M Y C$ acts in a complex with the transcription factor, early growth response 1 (EGR1), which was the fourth most downregulated gene between dexamethasone- and combination treated groups in our study. A study performed in the T-ALL cell line, Jurkat, showed that EGR1 binds and transactivates the BIM locus. ${ }^{64}$ However, in our microarray study EGR1 was strongly downregulated by the combination treatment and BIM was upregulated. In our study, GCS-3/dexamethasone-induced downregulation of C-MYC was not inhibited by the GR antagonist, RU486; however, the efficacy of the combination was inhibited. GCS-3/dexamethasone-induced upregulation of BIM was inhibited by RU486; therefore, BIM upregulation correlates with GCS-3/ dexamethasone combination efficacy and BIM does not appear to be a target of C-MYC in ALL-19 or ALL-54.

While it is important to develop new chemotherapeutics for the treatment of paediatric ALL, it is also useful to revisit and reinvigorate chemotherapeutic agents, such as glucocorticoids, which have a proven track record in paediatric ALL treatment. Reversing glucocorticoid resistance in paediatric ALL has the potential to improve the outcome for newly diagnosed high-risk patients with intrinsic glucocorticoid resistance, and patients with relapsed ALL and acquired resistance to glucocorticoids. Further development of GCS-3 may lead to a new class of drugs for the pharmacological reversal of glucocorticoid resistance in paediatric ALL, and ultimately to improved outcomes for patients with intrinsic and acquired glucocorticoid-resistant-lymphoid malignancies.

\section{ACKNOWLEDGEMENTS}

We thank Professor John E. Pimanda for kindly providing $\mathrm{CD}_{3} 4^{+}$cells from human cord blood and Dr. Julie A.I. Thoms for technical support. We also thank donors and staff from the Sydney Cord Blood Bank for supplying cord bloods. Children's Cancer Institute is affiliated with UNSW Sydney and the Sydney Children's Hospitals Network.

\section{AUTHOR CONTRIBUTIONS}

C.E.T. and R.B.L. designed the study; C.E.T., D.J. and C.M. generated and analysed the data; C.E.T. and R.B.L. interpreted the data and wrote the manuscript.

\section{ADDITIONAL INFORMATION}

Ethics approval and consent to participate All samples used in this manuscript were either purchased, established cell lines or patient-derived xenografts (passage $\geq 2$ ) that had previously been established with appropriate informed consent. All patient-derived xenografts were previously established under approval of the University of New South Wales Animal Care and Ethics Committee. Cord blood was obtained from the Sydney Cord Blood Bank under approval of the Prince of Wales Hospital (Reference number HREC 08/190). All donors consent to their sample being used for research and the Sydney Cord Blood Bank is licensed by the Therapeutic Goods Administration and accredited by the Foundation for Accreditation of Cellular Therapy. The study was performed in accordance with the Declaration of Helsinki.

Consent to publish This manuscript does not contain any individual person's data in any form.

Data availability All data generated or analysed during this study are included in this manuscript. Supplementary information is available at the British Journal of Cancer website. 
Competing interests The authors declare no competing interests.

Funding information This research was supported through the Priority-driven Collaborative Cancer Research Scheme and co-funded by Cancer Australia and The Kids' Cancer Project (Grant APP1129129). This research was also funded by the Anthony Rothe Memorial Trust, the National Health and Medical Research Council of Australia (NHMRC Fellowships APP1059804 and APP1157871 to RBL) and the Cancer Institute NSW (Early Career Fellowship 15/ECF/1-02 to D.J.). C.E.T. was funded by a Research Excellence Award from UNSW Sydney.

Supplementary information is available for this paper at https://doi.org/10.1038/ s41416-020-0824-8.

Note This work is published under the standard license to publish agreement. After 12 months the work will become freely available and the license terms will switch to a Creative Commons Attribution 4.0 International (CC BY 4.0).

Publisher's note Springer Nature remains neutral with regard to jurisdictional claims in published maps and institutional affiliations.

\section{REFERENCES}

1. Pui, C.-H., Yang, J. J., Bhakta, N. \& Rodriguez-Galindo, C. Global efforts toward the cure of childhood acute lymphoblastic leukaemia. Lancet Child Adolesc. Health 2, 440-454 (2018).

2. Pui, C.-H., Yang, J. J., Hunger, S. P., Pieters, R., Schrappe, M., Biondi, A. et al. Childhood acute lymphoblastic leukemia: progress through collaboration. J. Clin. Oncol. 33, 2938-2948 (2015).

3. Burke, W. \& Thummel, K. Precision medicine and health disparities: the case of pediatric acute lymphoblastic leukemia. Nurs. Outlook 67, 331-336 (2019).

4. Youlden, D. R., Gupta, S., Frazier, A. L., Moore, A. S., Baade, P. D., Valery, P. C. et al. Stage at diagnosis for children with blood cancers in Australia: application of the Toronto Paediatric Cancer Stage Guidelines in a population-based national childhood cancer registry. Pediatr. Blood Cancer 66, e27683 (2019).

5. Bhojwani, D. \& Pui, C.-H. Relapsed childhood acute lymphoblastic leukaemia. Lancet Oncol. 14, 205-217 (2013).

6. Pui, C.-H., Pappo, A., Gajjar, A. \& Downing, J. R. Redefining "rare" in paediatric cancers. Lancet Oncol. 17, 138-139 (2016).

7. Oskarsson, T., Söderhäll, S., Arvidson, J., Forestier, E., Montgomery, S., Bottai, M. et al. Relapsed childhood acute lymphoblastic leukemia in the Nordic countries: prognostic factors, treatment and outcome. Haematologica 101, 68-76 (2016).

8. Widjajanto, P. H., Sutaryo, S., Purwanto, I., Ven, P. M. V. \& Veerman, A. J. P. Early response to dexamethasone as prognostic factor: result from Indonesian childhood WK-ALL protocol in Yogyakarta. J. Oncol. 2012, 417941-417949 (2012).

9. Gao, J. \& Liu, W.-J. Prognostic value of the response to prednisone for children with acute lymphoblastic leukemia: a meta-analysis. Eur. Rev. Med. Pharmacol. Sci. 22, 7858-7866 (2018).

10. Jeha, S., Pei, D., Choi, J., Cheng, C., Sandlund, J. T., Coustan-Smith, E. et al. Improved CNS control of childhood acute lymphoblastic leukemia without cranial irradiation: St Jude Total Therapy Study 16. J. Clin. Oncol. 37, 3377-3391 (2019).

11. Heikamp, E. B. \& Pui, C.-H. Next-generation evaluation and treatment of pediatric acute lymphoblastic leukemia. J. Pediatr. 203, 14-24 (2018).

12. Gaipa, G., Basso, G., Biondi, A. \& Campana, D. Detection of minimal residual disease in pediatric acute lymphoblastic leukemia. Cytom. Part B 84, 359-369 (2013).

13. Chougule, R. A., Shah, K., Moharram, S. A., Vallon-Christersson, J. \& Kazi, J. U. Glucocorticoid-resistant B cell acute lymphoblastic leukemia displays receptor tyrosine kinase activation. NPJ Genom. Med. 4, 7-16 (2019).

14. Klumper, E., Pieters, R., Veerman, A., Huismans, D., Loonen, A., Hahlen, K. et al. In vitro cellular drug resistance in children with relapsed/refractory acute lymphoblastic leukemia. Blood 86, 3861-3868 (1995).

15. Lin, K.-T. \& Wang, L.-H. New dimension of glucocorticoids in cancer treatment. Steroids 111, 84-88 (2016).

16. Scheijen, B. Molecular mechanisms contributing to glucocorticoid resistance in lymphoid malignancies. Cancer Drug Resist. 2, 647-664 (2019).

17. Bachmann, P. S., Gorman, R., MacKenzie, K. L., Lutze-Mann, L. \& Lock, R. B. Dexamethasone resistance in B-cell precursor childhood acute lymphoblastic leukemia occurs downstream of ligand-induced nuclear translocation of the glucocorticoid receptor. Blood 105, 2519-2526 (2005).

18. Bachmann, P. S., Gorman, R., Papa, R. A., Bardell, J. E., Ford, J., Kees, U. R. et al. Divergent mechanisms of glucocorticoid resistance in experimental models of pediatric acute lymphoblastic leukemia. Cancer Res. 67, 4482-4490 (2007).

19. Bachmann, P. S., Piazza, R. G., Janes, M. E., Wong, N. C., Davies, C., Mogavero, A. et al. Epigenetic silencing of BIM in glucocorticoid poor-responsive pediatric acute lymphoblastic leukemia, and its reversal by histone deacetylase inhibition. Blood 116, 3013-3022 (2010).

20. Jing, D., Bhadri, V. A., Beck, D., Thoms, J. A. I., Yakob, N. A., Wong, J. W. H. et al. Opposing regulation of $\mathrm{BIM}$ and $\mathrm{BCL} 2$ controls glucocorticoid-induced apoptosis of pediatric acute lymphoblastic leukemia cells. Blood 125, 273-283 (2015).

21. Jing, D., Huang, Y., Liu, X., Sia, K. C. S., Zhang, J. C., Tai, X. et al. Lymphocytespecific chromatin accessibility pre-determines glucocorticoid resistance in acute lymphoblastic leukemia. Cancer Cell. 34, 906-921 (2018).

22. Bhadri, V. A., Cowley, M. J., Kaplan, W., Trahair, T. N. \& Lock, R. B. Evaluation of the NOD/SCID xenograft model for glucocorticoid-regulated gene expression in childhood B-cell precursor acute lymphoblastic leukemia. BioMed. Cent. Genomics 12, 565 (2011).

23. Toscan, C. E., Failes, T., Arndt, G. M. \& Lock, R. B. High-throughput screening of human leukemia xenografts to identify dexamethasone sensitizers. J. Biomol. Screen. 19, 1391-1401 (2014).

24. Liem, N. L. M., Papa, R. A., Milross, C. G., Schmid, M. A., Tajbakhsh, M., Choi, S. et al. Characterization of childhood acute lymphoblastic leukemia xenograft models for the preclinical evaluation of new therapies. Blood 103, 3905-3914 (2004).

25. Lock, R. B., Liem, N., Farnsworth, M. L., Milross, C. G., Xue, C., Tajbakhsh, M. et al. The nonobese diabetic/severe combined immunodeficient (NOD/SCID) mouse model of childhood acute lymphoblastic leukemia reveals intrinsic differences in biologic characteristics at diagnosis and relapse. Blood 99, 4100-4108 (2002).

26. Toscan, C. E., Rahimi, M., Bhadbhade, M., Pickford, R., McAlpine, S. R. \& Lock, R. B. Thioimidazoline based compounds reverse glucocorticoid resistance in human acute lymphoblastic leukemia xenografts. Org. Biomol. Chem. 13, 6299-6312 (2015).

27. El-Hoss, J., Jing, D., Evans, K., Toscan, C., Xie, J., Lee, H. et al. A single nucleotide polymorphism genotyping platform for the authentication of patient derived xenografts. Oncotarget 7, 60475-60490 (2016).

28. Tursky, M. L., Beck, D., Thoms, J. A. I., Huang, Y., Kumari, A., Unnikrishnan, A. et al. Overexpression of ERG in cord blood progenitors promotes expansion and recapitulates molecular signatures of high ERG leukemias. Leukemia 29, 819-827 (2015).

29. Bliss, C. I. \& Bartels, B. L. The determination of the most efficient response for measuring drug potency. Fed. Proc. 5, 167 (1946).

30. Inaba, H. \& Pui, C.-H. Glucocorticoid use in acute lymphoblastic leukaemia. Lancet Oncol. 11, 1096-1106 (2010).

31. Kuzelova, K., Grebenová, D. \& Brodská, B. Dose-dependent effects of the caspase inhibitor Q-VD-OPh on different apoptosis-related processes. J. Cell. Biochem. 112, 3334-3342 (2011).

32. Rhein, P., Scheid, S., Ratei, R., Hagemeier, C., Seeger, K., Kirschner-Schwabe, R. et al. Gene expression shift towards normal B cells, decreased proliferative capacity and distinct surface receptors characterize leukemic blasts persisting during induction therapy in childhood acute lymphoblastic leukemia. Leukemia 21, 897-905 (2007).

33. Yan, M., Kuang, X., Scofield, V. L., Shen, J., Lynn, W. S. \& Wong, P. K. Y. The glucorcorticoid receptor is increased in Atm-/- thymocytes and in Atm-/thymic lymphoma cells, and its nuclear translocation counteracts c-myc expression. Steroids 72, 415-421 (2007).

34. Jones, C. L., Bhatla, T., Blum, R., Wang, J., Paugh, S. W., Wen, X. et al. Loss of TBL1XR1 disrupts glucocorticoid receptor recruitment to chromatin and results in glucocorticoid resistance in a B-lymphoblastic leukemia model. J. Biol. Chem. 289, 20502-20515 (2014).

35. Bornhauser, B. C., Bonapace, L., Lindholm, D., Martinez, R., Cario, G., Schrappe, M. et al. Low-dose arsenic trioxide sensitizes glucocorticoid-resistant acute lymphoblastic leukemia cells to dexamethasone via an Akt-dependent pathway. Blood 110, 2084-2091 (2007).

36. Piovan, E., Yu, J., Tosello, V., Herranz, D., Ambesi-Impiombato, A., Da Silva, A. C. et al. Direct reversal of glucocorticoid resistance by AKT inhibition in acute lymphoblastic leukemia. Cancer Cell 24, 766-776 (2013).

37. Silveira, A. B., Laranjeira, A. B. A., Rodrigues, G. O. L., Leal, R., Cardoso, B. A., Barata, J. T. et al. PI3K inhibition synergizes with glucocorticoids but antagonizes with methotrexate in T-cell acute lymphoblastic leukemia. Oncotarget 6, 13105-13118 (2015).

38. Hall, C. P., Reynolds, C. P. \& Kang M. H. Modulation of glucocorticoid resistance in pediatric T-cell acute lymphoblastic leukemia by increasing BIM expression with the PI3K/mTOR inhibitor BEZ235. Clin. Cancer Res. 22, 621-632 (2016).

39. Wei, G., Twomey, D., Lamb, J., Schlis, K., Agarwal, J., Stam, R. W. et al. Gene expression-based chemical genomics identifies rapamycin as a modulator of MCL1 and glucocorticoid resistance. Cancer Cell 10, 331-342 (2006).

40. Zhang, C., Ryu, Y.-K., Chen, T. Z., Hall, C. P., Webster, D. R. \& Kang, M. H. Synergistic activity of rapamycin and dexamethasone in vitro and in vivo in acute lymphoblastic leukemia via cell-cycle arrest and apoptosis. Leuk. Res. 36, 342-349 (2012).

41. Nguyen, M., Marcellus, R. C., Roulston, A., Watson, M., Serfass, L., Murthy Madiraju, S. R et al. Small molecule obatoclax (GX15-070) antagonizes MCL-1 and 
overcomes MCL-1-mediated resistance to apoptosis. Proc. Natl Acad. Sci. USA 104, 19512-19517 (2007).

42. Heidari, N., Hicks, M. A. \& Harada, H. GX15-070 (obatoclax) overcomes glucocorticoid resistance in acute lymphoblastic leukemia through induction of apoptosis and autophagy. Cell Death Dis. 1, 76 (2010).

43. Bonapace, L., Bornhauser, B. C., Schmitz, M., Cario, G., Ziegler, U., Niggli, F. K. et al. Induction of autophagy-dependent necroptosis is required for childhood acute lymphoblastic leukemia cells to overcome glucocorticoid resistance. J. Clin. Invest. 120, 1310-1323 (2010)

44. Real, P. J., Tosello, V., Palomero, T., Castillo, M., Hernando, E., de Stanchina, E. et al. Gamma-secretase inhibitors reverse glucocorticoid resistance in $\mathrm{T}$ cell acute lymphoblastic leukemia. Nat. Med. 15, 50-58 (2009).

45. Hulleman, E., Kazemier, K. M., Holleman, A., VanderWeele, D. J., Rudin, C. M. Broekhuis, M. J. C. et al. Inhibition of glycolysis modulates prednisolone resistance in acute lymphoblastic leukemia cells. Blood 113, 2014-2021 (2009).

46. Eberhart, K., Renner, K., Ritter, I., Kastenberger, M., Singer, K., Hellerbrand, C. et al. Low doses of 2-deoxy-glucose sensitize acute lymphoblastic leukemia cells to glucocorticoid-induced apoptosis. Leukemia 23, 2167-2170 (2009).

47. Samuels, A. L., Heng, J. Y., Beesley, A. H. \& Kees, U. R. Bioenergetic modulation overcomes glucocorticoid resistance in T-lineage acute lymphoblastic leukaemia. Br. J. Haematol. 165, 57-66 (2014).

48. Cantley, A. M., Welsch, M., Ambesi-Impiombato, A., Sanchez-Martin, M., Kim, M.-Y., Bauer, A. et al. Small molecule that reverses dexamethasone resistance in T-cell acute lymphoblastic leukemia (T-ALL). ACS Medicinal Chem. Lett. 5, 754-759 (2014).

49. Neale, G., Su, X., Morton, C. L., Phelps, D., Gorlick, R., Lock, R. B. et al. Molecular characterization of the Pediatric Preclinical Testing Panel. Clin. Cancer Res. 14, 4572-4583 (2008).

50. Danilczuk, Z., Ossowska, G., Lupina, T., Cieślik, K. \& Zebrowska-Lupina, I. Effect of NMDA receptor antagonists on behavioral impairment induced by chronic treatment with dexamethasone. Pharmacol. Rep. 57, 47-54 (2005).

51. Mitchell, C. D., Richards, S. M., Kinsey, S. E., Lilleyman, J., Vora, A. \& Eden, T. O. B. Benefit of dexamethasone compared with prednisolone for childhood acute lymphoblastic leukaemia: results of the UK Medical Research Council ALL97 randomized trial. Br. J. Haematol. 129, 734-745 (2005).

52. Silverman, L. B., Gelber, R. D., Dalton, V. K., Asselin, B. L., Barr, R. D., Clavell, L. A. et al. Improved outcome for children with acute lymphoblastic leukemia: results of Dana-Farber Consortium Protocol 91-01. Blood 97, 1211-1218 (2001).
53. Strauss, A. J., Su, J. T., Kimball Dalton, V. M., Gelber, R. D., Sallan, S. E. \& Silverman, L. B. Bony morbidity in children treated for acute lymphoblastic leukemia. J. Clin. Oncol. 19, 3066-3072 (2001).

54. Wolkowitz, O. M. Prospective controlled studies of the behavioral and biological effects of exogenous corticosteroids. Psychoneuroendocrinology 19, 233-255 (1994).

55. Wang, Z., Malone, M. H., He, H., McColl, K. S. \& Distelhorst, C. W. Microarray analysis uncovers the induction of the proapoptotic BH3-only protein Bim in multiple models of glucocorticoid-induced apoptosis. J. Biol. Chem. 278, 23861-23867 (2003).

56. Schmidt, S., Rainer, J., Riml, S., Ploner, C., Jesacher, S., Achmüller, C. et al. Identification of glucocorticoid-response genes in children with acute lymphoblastic leukemia. Blood 107, 2061-2069 (2006).

57. Beesley, A. H., Firth, M. J., Ford, J., Weller, R. E., Freitas, J. R., Perera, K. U. et al. Glucocorticoid resistance in T-lineage acute lymphoblastic leukaemia is associated with a proliferative metabolism. Br. J. Cancer 100, 1926-1936 (2009).

58. Thulasi, R., Harbour, D. V. \& Thompson, E. B. Suppression of c-myc is a critical step in glucocorticoid-induced human leukemic cell lysis. J. Biol. Chem. 268, 18306-18312 (1993).

59. Medh, R. D., Webb, M. S., Miller, A. L., Johnson, B. H., Fofanov, Y., Li, T. et al. Gene expression profile of human lymphoid CEM cells sensitive and resistant to glucocorticoid-evoked apoptosis. Genomics 81, 543-555 (2003).

60. Planey, S. L., Abrams, M. T., Robertson, N. M. \& Litwack, G. Role of apical caspases and glucocorticoid-regulated genes in glucocorticoid-induced apoptosis of Pre-B leukemic cells. Cancer Res. 63, 172-178 (2003).

61. Wei-Chen Chen, D., Lynch, J. T., Demonacos, C., Krstic-Demonacos, M. \& Schwartz J.-M. Quantitative analysis and modeling of glucocorticoid-controlled gene expression. Pharmacogenomics 11, 1545-1560 (2010).

62. Reynolds, C., Roderick, J., Labelle, J., Bird, G., Mathieu, R., Bodaar, K. et al Repression of BIM mediates survival signaling by MYC and AKT in high-risk T-cell acute lymphoblastic leukemia. Leukemia 28, 1819-1827 (2014).

63. Wirth, M., Stojanovic, N., Christian, J., Paul, M. C., Stauber, R. H., Schmid, R. M. et al MYC and EGR1 synergize to trigger tumor cell death by controlling NOXA and BIM transcription upon treatment with the proteasome inhibitor bortezomib. Nucleic Acids Res. 42, 10433-10447 (2014).

64. Yun, S., Vincelette, N. D., Knorr, K. L. B., Almada, L. L., Schneider, P. A., Peterson, K. L. et al. 4EBP1/C-MYC/PUMA and NF-KB/EGR1/BIM pathways underlie cytotoxicity of mTOR dual inhibitors in malignant lymphoid cells. Blood 127, 2711-2722 (2016). 